\title{
Synthesis and Reactions of New Tellurium-substituted Terpenyl Compounds
}

\author{
Jacek Ścianowski, Anna Banach and Agata Pacuła \\ Department of Organic Chemistry, Faculty of Chemistry, Nicolaus Copernicus University, \\ 7 Gagarin Street, 87-100 Torun, Poland, jsch@chem.umk.pl
}

\begin{abstract}
In recent years, chalcogenides were widely used as efficient reagents and catalysts to create new carbon-oxygen, carbon-nitrogen and carbon-carbon bonds. Our previous research was focused on developing effective methods for the synthesis of new optically active organosulfur and organoselenium compounds derived from monoterpenes. Satisfying results prompted us to synthesize tellurium analogues. We have developed new methodologies for the synthesis of terpene ditellurides, tellurides, methyl terpenyl tellurides, and phenyl terpenyl tellurides from $p$-menthane, carane and pinane systems. The synthesis was based on the reaction of sodium telluride, sodium ditelluride, sodium benzenetellurolate, and sodium methanetellurolate with terpene tosylates, and chlorides. Additionally, terpene tellurides were converted in situ to telluronium ylides, and were used as reagents in asymmetric epoxydation. The best selectivity of epoxidation reaction was achieved for dicaranyl telluride.
\end{abstract}

Keywords: tellurides, ditellurides, monoterpenes

\section{Introduction}

Mono and dichalcogenides are very useful classes of organic compounds. More often they are considered as standard reagents or catalysts in organic synthesis, e.g. dichalcogenides can be simply converted into nucleophilic, electrophilic or radical reagents [1]. In our previous investigations we have shown a new methodology for the synthesis of dialkyl diselenides based on the reaction of sodium diselenide with alkyl tosylates and chlorides [2]. Particularly interesting were the applications of our methodology for the synthesis of optically active selenides and diselenides derived from monoterpenes. We have obtained a series of selenium derivatives from $p$-menthane, carane, and pinane systems [3-7]. Analogously we have prepared a sulphur terpenyl derivatives [8]. We have demonstrated that diterpenyl diselenides e.g. dineomenthyl diselenide $\mathbf{1}$ can be simply converted into electrophilic selenium reagents 2 by the reaction with bromine, than exchange with silver salts, or to nucleophilic reagents 3 by the reaction with sodium borohydride (Scheme 1). Electrophilic reagents were tested in the addition to the double bonds (path a) [3-7] or selenocyclization reaction with the formation of new carbon-oxygen bonds [9], but nucleophilic reagents were 
used for the synthesis of allylic selenides than via oxidation for the synthesis of chiral allylic alcohols (path b) [10].

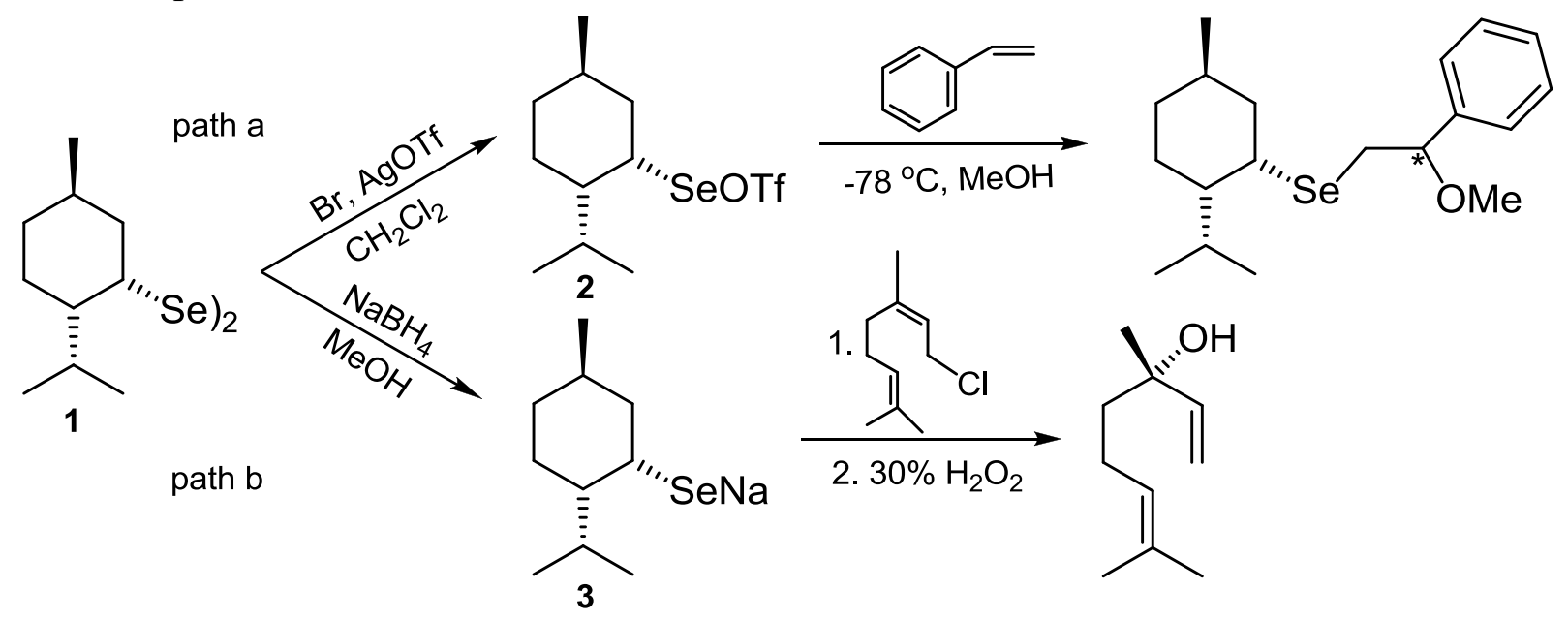

Scheme 1. Applications of dineomenthyl diselenide 1

Now we present our results for the synthesis of symmetrical and unsymmetrical ditellurides and tellurides obtained by analogical methodology based on the reaction of terpenyl tosylates and chlorides with corresponding tellurium reagents. We have decided to use tellurides for the tellurium-mediated asymmetric epoxidation.

\section{Results and Discussion}

We have started our research from the synthesis of sodium telluride $\mathbf{4}$ and sodium ditelluride 5. We have developed new two step methodology based on the reduction of tellurium with $\mathrm{NaBH}_{4}$, than addition of one equivalent of tellurium (Scheme 2). Sodium telluride and sodium ditelluride were used for further reactions without isolation from the reaction mixture.

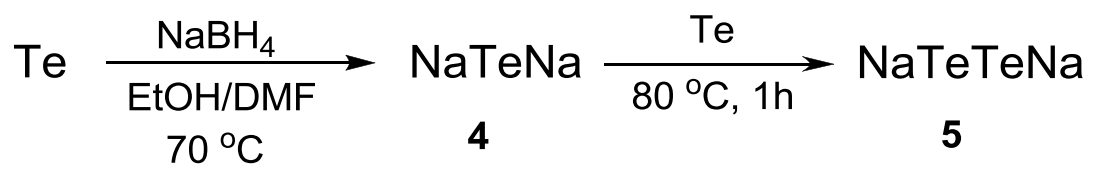

Scheme 2. Synthesis of sodium telluride $\mathbf{4}$ and sodium ditelluride 5

Sodium ditelluride was used for the synthesis of optically active diterpenyl ditellurides. We have started our investigation from the synthesis of dineomenthyl ditelluride 6 by the reaction of menthyl tosylate 7 with sodium ditelluride 5. Epimeric dimenthyl ditelluride 10 was obtained using neomenthyl chloride $\mathbf{9}$ for the reaction. Corresponding tosylate 7 and chloride 9 were prepared by standard methodologies described in previous papers [3]. The reactions were carried out in $100{ }^{\circ} \mathrm{C}$ in a mixture of EtOH/DMF, by $1 \mathrm{~h}$ for menthyl tosylate and $2 \mathrm{~h}$ for neomenthyl chloride. Better yield was obtained using corresponding tosylate than chloride. 


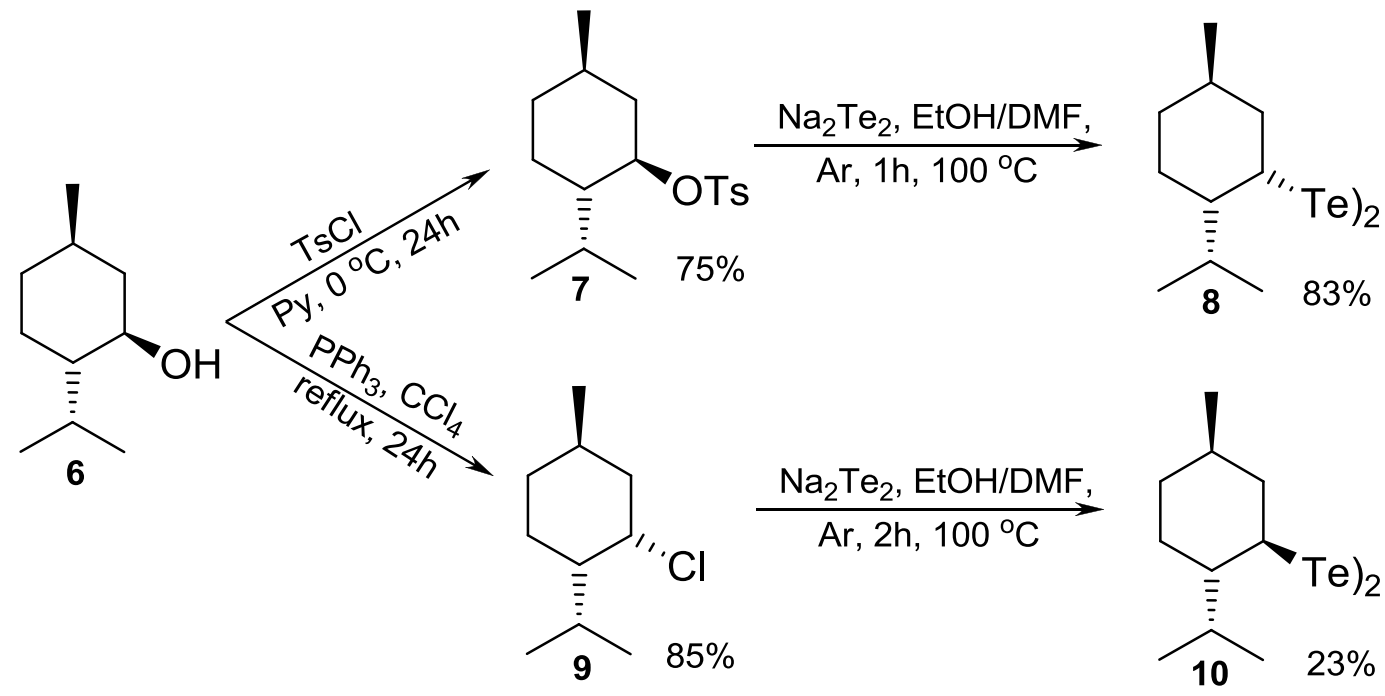

Scheme 3. Synthesis of dineomenthyl ditelluride $\mathbf{8}$ and dimenthyl ditelluride $\mathbf{1 0}$

The structures of ditellurides were confirmed by ${ }^{1} \mathrm{H},{ }^{13} \mathrm{C}$ NMR, and additionally X-ray analysis for dineomenthyl ditelluride 8 (Figure 1).

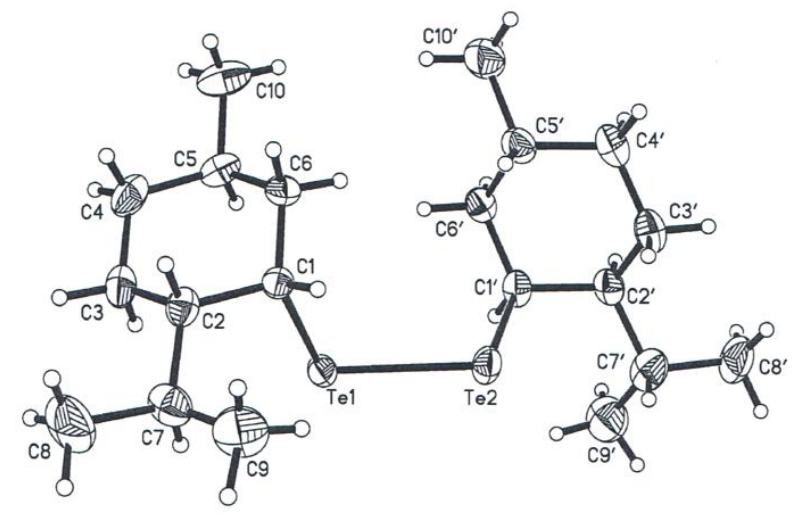

Fig.1. The structure of dineomenthyl ditelluride $\mathbf{8}$

Using this methodology a series of ditellurides was obtained from carane 11, and 12, and pinane 13 systems (Figure 2).
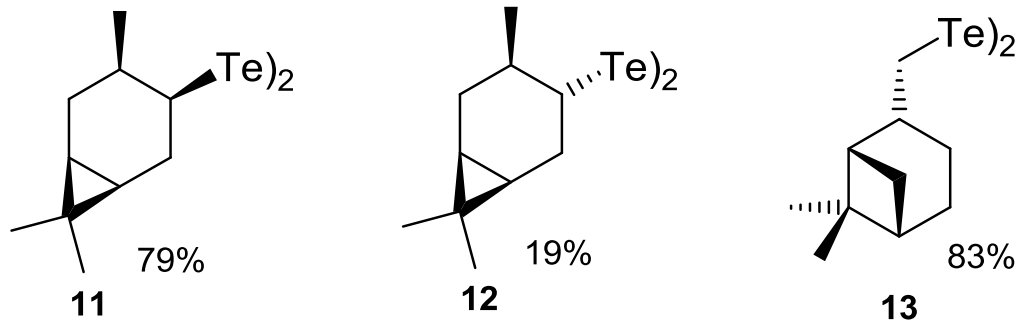

Fig.2. Structures of ditellurides 11-13 
In the second part of our work we have prepared symmetrical and unsymmetrical tellurides. Neomenthyl telluride $\mathbf{1 4}$ has been prepared by the reaction of mentyl tosylate $\mathbf{6}$ with sodium telluride 4 . This structure was confirmed by X-ray analysis (Scheme 4).
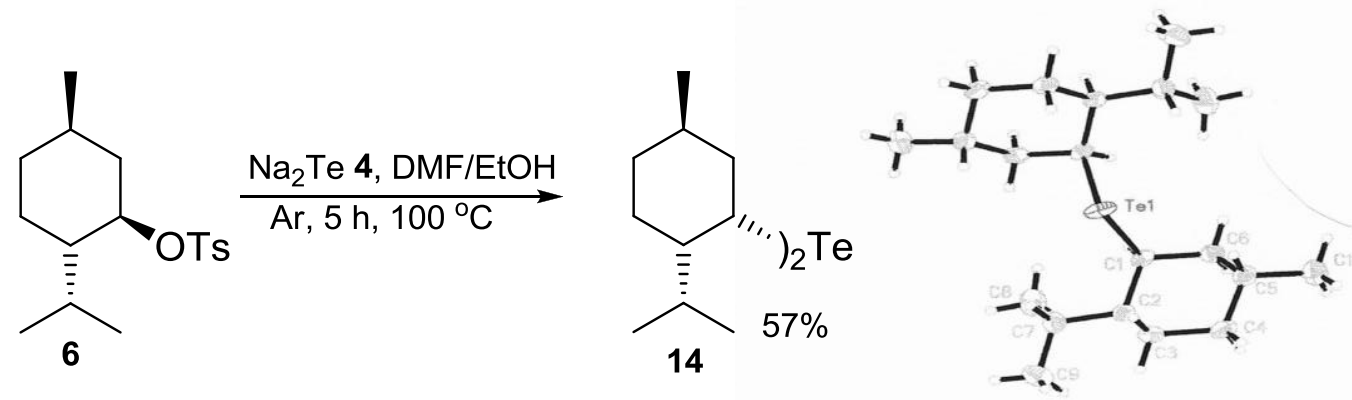

Scheme 4. Synthesis and structure of dineomenthyl ditelluride 14

Methyl neomenthyl telluride $\mathbf{1 5}$ and phenyl neomentyl telluride $\mathbf{1 6}$ have been prepared by the reaction of sodium methanetellurolate, and sodium benzenetellurolate, generated in situ from dimethyl ditelluride or diphenyl ditelluride and $\mathrm{NaBH}_{4}$, with tosylate 6 (Scheme 5).

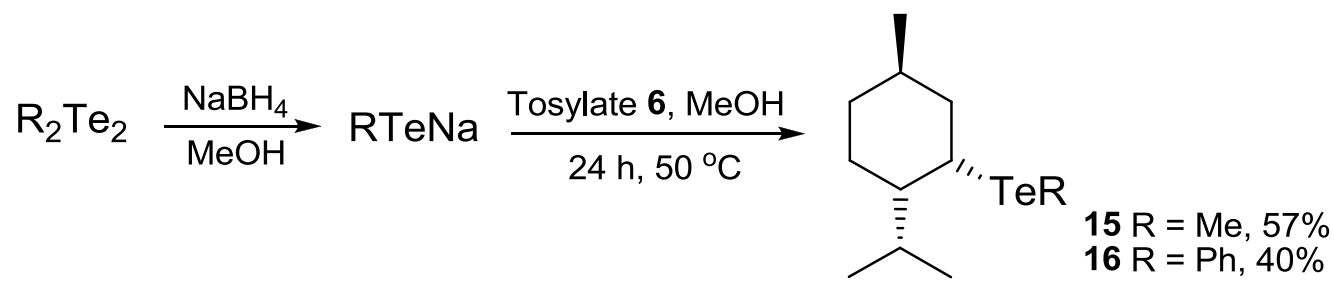

Scheme 5. Syntheses of telluride $\mathbf{1 5}$ and $\mathbf{1 6}$

These methodologies we have also used for the synthesis of diterpenyl tellurides 17, 18, methyl terpenyl tellurides 19, 20 and phenyl terpenyl tellurides 21, 22 from carane and pinane series. Obtained compounds are presented at Figure 3.

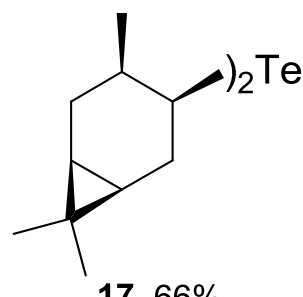

$17,66 \%$

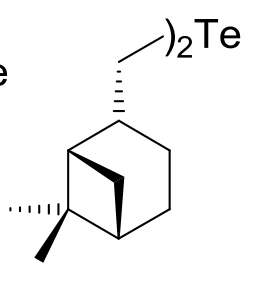

$18,41 \%$

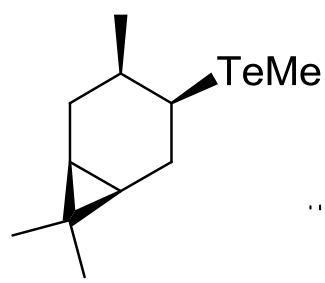

$19,52 \%$

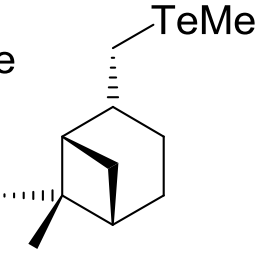

$20,52 \%$<smiles>C[C@@H]1CC2C(C[C@H]1[TeH])C2(C)C</smiles>

Fig. 3. Structures of terpenyl tellurides 17-22 
Tellurides 14-22 were used for the tellurium ylide-mediated asymmetric epoxidation. Telluronium ylides were generated in situ by addition of benzyl bromide, than $\mathrm{NaOH}$. Reaction with benzaldehyde gave epoxystilbene (Scheme 6). The results of epoxidation are collected in Table 1.

$\mathrm{RTeR}^{1} \stackrel{\text { 1eq. } \mathrm{PhCH} \mathrm{H}_{2} \mathrm{Br}, 2 \text { eq. } \mathrm{PhCHO}}{\mathrm{CH}_{3} \mathrm{CN}, \mathrm{NaOH}, 3 \mathrm{~d}}$

14-22

$\mathrm{R}$ - terpene

$\mathrm{R}^{1}-\mathrm{Me}, \mathrm{R}, \mathrm{Ph}$

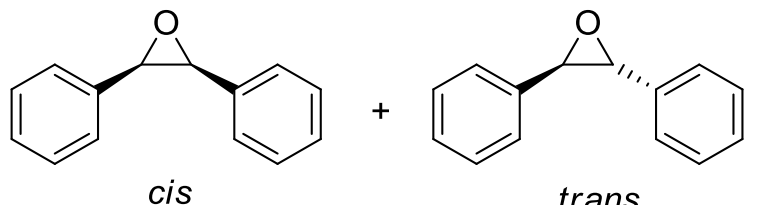

trans

Scheme 6. Epoxidation with the use of tellurides 14-22

Table 1. Results of asymmetric epoxidation

\begin{tabular}{ccccc}
\hline Entry & Telluride & Yield [\%] & Cis/trans [\%] & Ee [\%] \\
\hline 1 & $\mathbf{1 4}$ & 9 & $50 / 50$ & $16(S, S)$ \\
2 & $\mathbf{1 7}$ & 47 & $11 / 89$ & $68(S, S)$ \\
3 & $\mathbf{1 8}$ & 22 & $59 / 41$ & $6(R, R)$ \\
5 & $\mathbf{1 5}$ & 40 & $44 / 56$ & $36(S, S)$ \\
6 & $\mathbf{1 9}$ & 5 & $9 / 91$ & $10(S, S)$ \\
7 & $\mathbf{2 0}$ & 22 & $59 / 41$ & $6(R, R)$ \\
8 & $\mathbf{1 6}$ & 13 & $39 / 61$ & $36(S, S)$ \\
\hline & $\mathbf{2 2}$ & 10 & $9 / 91$ & $4(R, R)$ \\
\hline
\end{tabular}

The best result of asymmetric epoxidation with the use of telluronium ylides was obtained for the reaction of dicaranyl telluride 17.

\section{Conclusions}

In this communication we have presented a convenient methodology for the synthesis of sodium telluride and ditelluride by the simple reduction of tellurium with $\mathrm{NaBH}_{4}$ and addition of another equivalent of tellurium. The reaction of sodium telluride and ditelluride with terpenyl tosylates gave with good yield diterpenyl telluride and diterpenyl ditellurides. Additionally the reaction of sodium methanetellurolate, and sodium benzenetellurolate with terpenyl tosylates gave methyl and phenyl terpenyl tellurides. All tellurides were tested in asymmetric epoxidation. The best result was obtained for bicyclic telluride from carane series. 


\section{References}

[1] (a) Pellissier, H. Chiral Sulfur Ligands - Asymmetric Catalysis, RSC Publishing: Cambridge, 2009. (b) Drabowicz, J.; Lewkowski, J.; Ścianowski, J. Selenium Compounds with Valency Higher than Two in Organoselenium Chemistry, Wirth, T. (ed.) WILEY-VCH: Weincheim, 2012 p.191-256. (c) Petragnani, N.; Stefani, H. A. Tellurium in Organic Synthesis, Academic Press: London, 2007.

[2] Ścianowski, J. Tetrahedron Lett. 2005, 46, 3331-3334.

[3] Ścianowski, J.; Rafiński, Z.; Wojtczak A. Eur. J. Org. Chem. 2006, 14, 3216-3225.

[4] Rafiński, Z.; Ścianowski J. Tetrahedron: Asymmetry 2008, 19, 1237-1244.

[5] Rafiński, Z.; Ścianowski, J.; Wojtczak A. Letters in Organic Chemistry 2009, 6, 321-328.

[6] Ścianowski, J.; Rafiński, Z.; Szuniewicz, A.; Wojtczak, A. Tetrahedron 2009, 65, 10162-

10174.

[7] Ścianowski, J.; Rafiński, Z.; Wojtczak, A.; Burczyński K. Tetrahedron: Asymmetry 2009, 20, 2871-2879.

[8] Banach, A.; Ścianowski, J.; Ozimek, P. Phosphorus, Sulfur, 2013 DOI: 10.1080/ 10426507.2013.819867.

[9] Rafiński, Z.; Ścianowski, J.; Wojtczk A. Tetrahedron: Asymmetry 2008, 19, 223-230.

[10] Ścianowski, J.; Rafalski, J.; Banach, A.; Czaplewska, J.; Komoszyńska, A. Tetrahedron: Asymmetry 2013, 24, 1089-1096. 